\title{
Human Activities and their Attendant Impacts on the Riparian Ecosystem of the Stream, a Case Study of Ogangan Stream in Igede-Ekiti, Ekiti State, Nigeria
}

\author{
A. A. Shittu ${ }^{1 *}$, O. O. Ojo ${ }^{1}$, A. F. Ado ${ }^{1}$ and O. A. Bamisaiye ${ }^{2}$ \\ ${ }^{1}$ Department of Geography and Planning Science, Ekiti State University, Ado Ekiti, Ekiti State, \\ Nigeria. \\ ${ }^{2}$ Department of Physical Planning and Development Matters, Ekiti State Ministry of Lands, Housing \\ and Urban Development, Ado Ekiti, Ekiti State, Nigeria.
}

Authors' contributions

This work was carried out in collaboration among all authors. Author AAS designed the study, performed the statistical analysis, wrote the protocol and wrote the first draft of the manuscript. Authors AFA and OOO managed the analyses of the study. Author OAB managed the literature searches. All authors read and approved the final manuscript.

Article Information

DOI: 10.9734/AJGR/2019/v2i430091

Editor(s):

(1) Dr. Xu Chong, Professor, Institute of Geology, China. Reviewers:

(1) Guoming Du, Northeast Agricultural University, China. (2) Adeleke Benjamin Oluwafemi, Obafemi Awolowo University, Nigeria. Complete Peer review History: http://www.sdiarticle4.com/review-history/52857

\begin{abstract}
This paper examined human activities and their attendant impacts on the riparian ecosystem of the stream, a case study of ogangan stream in Igede-Ekiti, Ekiti State, Nigeria with the major aim to assess the rate of increase in human activities and its attendant impacts on the riparian ecosystem of the stream. The study was carried out in 2019 and employed the collection of data from both primary and secondary sources. Sixty (60) copies of questionnaire were administered for this study through random sampling of the respondents; data collected were presented in statistical tabulated tables, charts and graphical representation. Descriptive statistics such as pie chart, distribution curve, frequencies, and percentages were employed to analyze data. The outcome of the study revealed that, human activities were rapidly increasing in the riparian zone than ever, as more people spread to reside in the area which has detrimental effects on the riparian zone of the river. The study concluded that this unprecedented rate of increase in human activities in the study area
\end{abstract}


was degrading the capability of the riparian zone to provide ecosystem services and therefore recommended that the State Government should implement law for the protection of riparian habitat. This law should be accompanied with implementing mechanism for its sustainability.

Keywords: Human activities; ecosystem; stream and Riparian area.

\section{INTRODUCTION}

Human being shape the land through increasing populations, agricultural expansion, mineral and forest resource excavation, changing the flow of rivers, and with layers of industrial and urban infrastructure [1]. Over the course of history, human beings have had a changeable relationship to the land. Early humans are believed to have used the land with little modification for shelter, food gathering, and defensive aims. It wasn't until the domestication of plants and animals approximately 10,000 years ago that land use involved extensive changes in the landscape. With domestication, came large-scale clearing for both settlement and agriculture. Growing populations built structures on the land (or out of the land) for shelter, defense and worship, and altered the existing land cover and the course of waterways for food, power, and transportation [2].

Food and Agricultural Organization (1998) defines that land use is characterized by the arrangements, activities and inputs people undertake in a certain land cover type to produce, change or maintain it. Thus, this expression establishes a direct link between land cover and the actions of people in their environment.

In many instances, the biological and physical make-up of the land contributes to how it is used; lands with rich soils and close to water bodies are most suitable for farming while lands prone to flooding are less suitable for settlement. Large cities, for example, are often located adjacent to an ocean or river, providing essential water, and access for food, sewer, industrial, and economic purposes [3].

A riparian zone or riparian area is the interface between land and a river or stream. The word riparian is derived from Latin "Ripa" meaning river bank. Riparian refers to the vegetation, habitats and ecosystems associated with bodies of water (streams, springs or lakes) or dependent on the existence of perennial, intermittent, or ephemeral surface or subsurface water drainage
[4]. Riparian areas are transitional between terrestrial and aquatic ecosystems and are distinguished by gradients in biophysical conditions, ecological processes, and biota. They are areas through which surface and subsurface hydrology connect water bodies with their adjacent uplands. They include those portions of terrestrial ecosystems that significantly influence exchanges of energy and matter with aquatic ecosystems (i.e., a zone of influence). Riparian areas are adjacent to perennial, intermittent, and ephemeral streams, lakes, and estuarine-marine shorelines $[5,6]$.

Riparian is also the proper nomenclature for one of the fifteen terrestrial biomes of the earth. Plant habitats and communities along the river margins and banks are called riparian vegetation, characterized by hydrophilic plants (Enanga, 2011).

\section{STATEMENT OF THE RESEARCH PROBLEM}

The riparian zone is one of the most dynamic regions of the landscape, being subjected to regimes of disturbance and change. Riparian vegetation has evolved to cope with the stresses associated with such regimes. Riparian vegetation has been managed poorly in the past throughout the world. Various human activities have caused much indigenous riparian vegetation to be cleared from stream banks and floodplains for 'improvements' associated with agricultural production, urbanization, irrigation, river navigation, flood mitigation and river engineering (Erskine, 2001).

The widespread disturbance of riparian zones has compromised the genetic and ecological integrity of many species and communities of riparian vegetation and has contributed to detrimental impacts on the in-stream ecology and geomorphology of many rivers. In addition, many exotic species of vegetation have been planted in the riparian zone, particularly in the tropical regions of the world, resulting in major detrimental impacts, both genetically and ecologically, on the riparian zone (Erskine, 2001). 


\section{RESEARCH QUESTION}

What are the human activities and its attendant impacts on the riparian ecosystem?

\section{OBJECTIVE OF THE STUDY}

The objective of the study is to assess the human activities and its attendant impacts on the riparian ecosystem of the stream.

\section{THE STUDY AREA}

\subsection{Location and Boundaries}

Igede-Ekiti lies within latitudes $7^{\circ} 39^{\prime}$ and $7^{\circ} 41^{\prime}$ North of the Equator and longitudes $5^{\circ} 7^{\prime}$ and $5^{\circ} 8^{\prime}$ East of the Greenwich Meridian. It is the Headquarters of Irepodun/Ifelodun Local Government Area of Ekiti state. It shares political boundaries in the North with Awo-Ekiti, in the South with Ilawe-Ekiti, in the East with Iyin-Ekiti and West with Aramoko-Ekiti. It is at a distance of about 15 kilometres from Ado-Ekiti, the state capital and 64 kilometers from Akure, the capital of Ondo state. Igede-Ekiti covers a land area about $10 \mathrm{~km}^{2}$. The population according to 1966 census stood at 31, 041 people and had tremendously increases ever since. The current population of Igede-Ekiti is about 87,282.

\subsection{Climate}

The entire zone lies within the humid tropics hence experiences a hot-wet climate, a characteristics feature of a typical rainforest belt of the southwestern Nigeria. An annual mean sea level temperature of $27^{\circ} \mathrm{C}\left(53.6^{\circ} \mathrm{F}\right)$ with annual range between $-17.2^{\circ} \mathrm{C}$ and $-14.4^{\circ} \mathrm{C}$ were common. Total annual rainfall varies between $1500 \mathrm{~mm}$ and $2700 \mathrm{~mm}$, displaying two peaks (double maxima) in July and September coinciding with the passage of the overhead sun, with a short dry spell or August Break lying between both orographic/relief and convectional rainfalls with lightening and thunders at the onset and retreat regimes. High relative humidity of about $80 \%$ is common. Extreme cold (Harmattan) in December and January is predominant.

\subsection{Physiography}

Igede-Ekiti is situated on relatively high land with Esu Hill being the highest peak and an outcrop at Oke Aga in Odogede Quarters. Igede, by this scenario, became a watershed and sources of many important rivers; e.g River Osun (The revered "Osun Osogbo"), Orunro, Elemi, Inansi, Ogangan (case study), Ogburuu, Ogbese, Ebisi, Eripon, Apon, Afunnigboya, Olutogin, Amugbadagbe, Eriki, Eeriologbo, e.t.c. they all possess potentials for fishery, dams and tourism development. (IPA, IDC 2013).

\subsection{Vegetation}

The study area exhibits an equatorial floral phenomenon in most parts until of recent due to human intervention (clearing, felling and burning) where traces of derived savanna are becoming noticeable. Indigenous trees include; Iroko, Idigbo, Oganwo, Mahogany, Olee, Oriro, etc. intermingled with shorter trees and oil palms in some open locations. Infacts, savanna vegetation is fast overtaking and displacing the aborigine forest (IPA, IDC 2013).

\section{LITERATURE REVIEW}

Generally there is a variation in land use activities from upstream to downstream. Upstream is dominated by indigenous forest characterized by dense network of trees and bushes with little human disturbance. From the edge of the forests towards midstream, the land opens up to a rich upland agricultural area of extensive and intensive farming characterized by tea plantation and few human settlements. Moving downstream, grazing and mixed agricultural farming predominate with more permanently settled small scale farmers and urban set-up with high population and economic activities. Upstream riparian vegetation was least disturbed with native vegetation present on both sides of the river, intact canopy and with continuous woody vegetation along the riparian zone, dense ground cover and river banks in natural condition. Midstream riparian vegetation is in poor condition characterized by isolated woody vegetation, limited ground cover and disturbed banks. In addition there is a high disturbance of the riparian zone by stock or through the intrusion of exotic species, although some native species remain. Downstream riparian vegetation is severely disturbed on both sides as indicated by reduced and absence of riparian vegetation.

Alaigba, [7] in their study explained that recent development and expansion of paved surfaces as a result of urban growth has resulted in encroachment of riparian corridors, the immediate effect of which poses flood risk to affected areas. Results from the study indicated 
that urban and agricultural land uses had encroached significantly on the riparian corridor and had disrupted the ecosystem services of the corridor. Results also indicated that major parts of the watershed had low flood risk but serious encroachment exists therein. Studies have shown that riparian habitats are very important for water quality, flood and erosion control. Groundwater nutrients can be retained in a riparian habitat as a result of plant uptake, microbial processes and organic matter absorption. Nutrient uptake as well as removal by soil and vegetation in riparian habitats prevents outputs of agricultural lands from entering the stream channel. They also stated that the delineation and extent of riparian areas vary in part because of their inherently complex and dynamic character.

Chambers [8] stated that degradation of riparian zones is a result of complex interrelated responses from geomorphic, hydrologic and biotic processes to climate change and natural and anthropogenic disturbances. He asserted that the disturbances can alter the hydrological or sediment regime of the river/stream system and produce changes in the physical properties of riparian ecosystems such as stream channel characteristics, and surface and ground water interactions. He opined that human activities such as agriculture, harvesting of riparian flora and hunting of riparian fauna, grazing and industrial discharges have a great impact on riparian ecosystems. Direct discharge of untreated waste from industries, domestic and urban sources into lakes contribute to various forms of pollution, eutrophication, suspended solids, sedimentation and pesticide residues leached from soils and agricultural plantations. He also stated that human impact such as dams; deforestation and water use practices pose serious threats to water availability to downstream populations. Degradation of riparian zones not only affects the riparian area but also the surface and ground water resources and the aquatic fauna and flora; and the terrestrial ecosystem. Thus, the riparian zone is increasingly seen as ecologically important in the environment.

Vivek and Marina [9] explained that Riparian zones worldwide have been subject to a lot of disturbances such as soil compaction as a result of road and pathway construction; erecting of buildings, especially in urban areas; and reduction in habitat and habitat heterogeneity for the invertebrates and mammals that live in riparian zones. They recommended the most common approach to protect stream and riparian areas as using riparian buffers. Also the riparian managers need to use management strategies and monitoring methods that are compatible with their objectives and the response potential of each river or stream.

\section{RESEARCH METHODS}

Data for this study were collected from both primary and secondary sources. Primary sources of data for this study were mainly observation. Initial reconnaissance was carried out in the study area to ascertain various human activities in the riparian zone, in-depth oral interview of the community members for first-hand information, especially residents and farmers very close to the river. Additional information from secondary sources was derived internet materials. Information on major impacts of human activities on the riparian area was collected using a structured questionnaire administered to the sampled households living in the immediate vicinity and within $1 \mathrm{~km}$ on either side of the stream bank. Sixty (60) copies of questionnaire were administered for this study through random sampling of the respondents. The data collected were presented in statistical tabulated tables, charts and graphical representations to assess various human activities classification and predominant human activities. Descriptive statistics such as pie chart, distribution curve, frequencies, and percentages were employed to analyze data in this research.

\section{RESULTS AND DISCUSSION}

\subsection{Human Activities Impact on the Riparian Corridor of the River}

Table 1 shows that $26.7 \%$ of the respondents strongly agreed that human activities within the stream bank of Ogangan River have altered the productivity of the riparian area. $51.7 \%$ agreed that human activities within the stream bank of Ogangan River have altered the productivity of the riparian area. $3.3 \%$ were undecided. $16.7 \%$ disagreed while $1.6 \%$ strongly disagreed.

The respondents affirmed that the increase human activities have reduced the level of productivity of the area, it was observed that some of the plants very close to the riparian zone are having stunted growth, this also supports the view of the respondents. 
Table 1. Effect of Human activities on Ogangan Riparian area productivity

\begin{tabular}{|c|c|c|}
\hline Response & Frequency & $\begin{array}{l}\text { Percentage } \\
\text { (\%) }\end{array}$ \\
\hline $\begin{array}{l}\text { Strongly Agree } \\
\text { (SA) }\end{array}$ & 16 & 26.7 \\
\hline Agree $(A)$ & 31 & 51.7 \\
\hline Undecided (UD) & 2 & 3.3 \\
\hline Disagree (D) & 10 & 16.7 \\
\hline $\begin{array}{l}\text { Strongly } \\
\text { Disagree (SD) }\end{array}$ & 1 & 1.6 \\
\hline Total & 60 & 100 \\
\hline
\end{tabular}

Table 2. Increased pollution from human activities

\begin{tabular}{lll}
\hline Response & Frequency & $\begin{array}{l}\text { Percentage } \\
(\%)\end{array}$ \\
\hline Strongly Agree & 16 & 26.7 \\
(SA) & & \\
Agree (A) & 28 & 46.7 \\
Undecided (UD) & 2 & 3.3 \\
Disagree (D) & 13 & 21.7 \\
$\begin{array}{lll}\text { Strongly } \\
\text { Disagree (SD) }\end{array}$ & 1 & 1.6 \\
\hline Total & 60 & 100 \\
\hline \multicolumn{2}{r}{ Source: Author's Fieldwork (2019) }
\end{tabular}

Human activities also resulted to pollution of Ogangan River (Fig. 4) and in Table 2. $26.7 \%$ of the respondents strongly agreed that increasing landuse activities has resulted to pollution of the river. $46.7 \%$ of the respondents agreed that increasing landuse activities has resulted to pollution of the river. $3.3 \%$ of the respondents were undecided, $21.7 \%$ disagreed while $1.6 \%$ strongly disagreed. It was observed that at the riparian zone, people are dumping dirt along the area. Waste materials from the agricultural activities within this area contributes to pollution in this area.

Table 3 shows that $25 \%$ of the respondent strongly agreed that the volume of water in Ogangan River has reduced drastically since the onset of various human activities. $53.3 \%$ agreed that the volume of water in Ogangan River has reduced drastically since the onset of various human activities. $1.4 \%$ were undecided, $16.7 \%$ disagreed while $3.3 \%$ strongly disagreed. It was gathered from the people that the river is used for various irrigation farming within the area, and this reduces the volume of the river. It was seen from the visit to this area that people do fetch the water for several domestic uses and this also contributes to the reduction of the volume of the river.

Table 3. Human activities reduces water volume in Ogangan River

\begin{tabular}{|c|c|c|}
\hline Response & Frequency & $\begin{array}{l}\text { Percentage } \\
\text { (\%) }\end{array}$ \\
\hline $\begin{array}{l}\text { Strongly Agree } \\
\text { (SA) }\end{array}$ & 15 & 25 \\
\hline Agree $(A)$ & 32 & 53.3 \\
\hline Undecided (UD) & 1 & 1.4 \\
\hline Disagree (D) & 10 & 16.7 \\
\hline $\begin{array}{l}\text { Strongly } \\
\text { Disagree (SD) }\end{array}$ & 2 & 3.3 \\
\hline Total & 60 & 100 \\
\hline
\end{tabular}

Table 4 shows that $28.3 \%$ of the respondents strongly agreed that the human activities on the riparian zone of Ogangan River has led to the extinction of most indigenous species that inhabited the area. $50 \%$ of the respondents agreed that various human activities on the riparian zone of Ogangan River has led to the extinction of most indigenous species that inhabited the area. $5 \%$ of the respondents were undecided. $13.3 \%$ of the respondents disagreed while $3.3 \%$ of the respondents strongly disagreed. The people made it known that there were some species of animals that inhabited in this area in the past that are now nowhere to be found, this was as a result of the persistent hunting that is been done in this area for a long time, therefore resulting to extinction of some of the animal species in the riparian area.

Table 4. Human activities results to extinction of the Riparian indigenous species

\begin{tabular}{lll}
\hline Response & Frequency & $\begin{array}{l}\text { Percentage } \\
(\%)\end{array}$ \\
\hline Strongly Agree & 17 & 28.3 \\
(SA) & & \\
Agree (A) & 30 & 50 \\
Undecided (UD) & 3 & 5 \\
Disagree (D) & 8 & 13.3 \\
$\begin{array}{l}\text { Strongly } \\
\text { Disagree (SD) }\end{array}$ & 2 & 3.3 \\
\hline \multicolumn{2}{l}{ Total Source: Author's Fieldwork (2019) }
\end{tabular}

Human activities around the riparian zone of Ogangan River can reduce the lifespan of the river. $28.3 \%$ of the respondents strongly agreed that the lifespan of Ogangan River can reduce due to human activities around it. $63.3 \%$ of the respondents agreed that the lifespan of Ogangan 
River can reduce due to human activities around it. $3.3 \%$ of the respondents were undecided, $3.3 \%$ disagreed while $1.7 \%$ strongly disagreed as shown in Table 5 . If these human activities persists in the riparian zone, there is great endangerment of the lifespan of the riparian zone, for instance, it was gathered that during the dry season, there is great reduction in the volume of the river as a result of increase in human activities within the area. The respondents also made it clear that construction activities is getting closer to the zone and this puts the continuity of this riparian zone in great threat.

Riparian zones have been discovered to be very rich ecosystem with fullness of biodiversity, and as such plays important role in the environment. The riparian zone of Ogangan river is not left out of this fact, especially when it was unaltered by human activities. (Fig. 1) shows the riparian zone of Ogangan river from the upper stream through the middle stream to the downstream. Ogangan River is one of the surface water that provides domestic and agro-industrial water needs to an estimated population of not less than 250 persons in the vicinity of the river. Various human activities within the zone have resulted to drastic changes in the past few years. The life which existed in the riparian area of the river several years ago, before the intrusion of human as a result of urban development in the area, is no more, as major component of the riparian zone are extinct leaving the river exposed to various harmful threats.

\section{Table 5. Human activities reduces the lifespan of Ogangan River}

\begin{tabular}{lll}
\hline Response & Frequency & $\begin{array}{l}\text { Percentage } \\
(\%)\end{array}$ \\
\hline Strongly Agree & 17 & 28.3 \\
(SA) & & \\
Agree (A) & 38 & 63.3 \\
Undecided (UD) & 2 & 3.3 \\
Disagree (D) & 2 & 3.3 \\
Strongly & 1 & 1.7 \\
Disagree (SD) & & \\
\hline \multicolumn{2}{l}{ Total Source: Author's Fieldwork (2019) }
\end{tabular}

Human activities such as agricultural, residential, industrial, with agricultural being the dominant were identified in the riparian zone of Ogangan river. Residents around the River make use of the water for drinking, cooking, bathing, laundry and some for irrigation (Fig. 2). Water from the River is used for washing farm produce such as

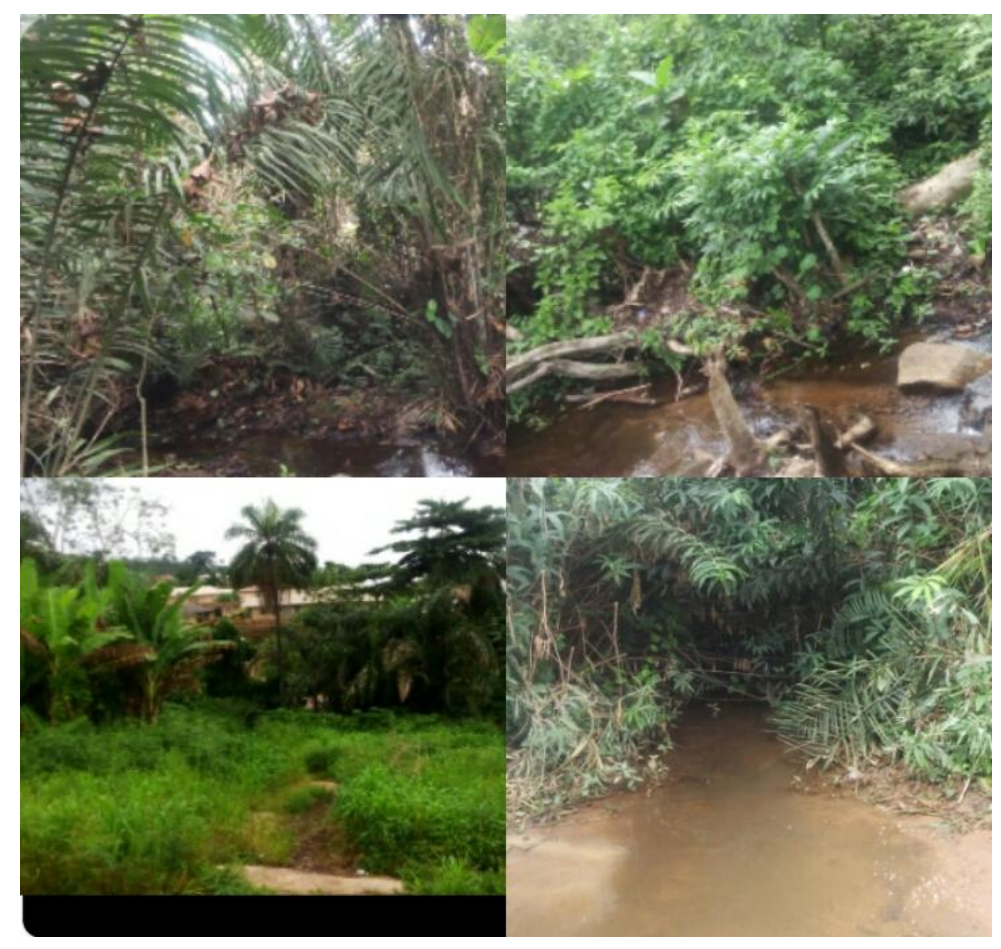

Fig. 1. Riparian zone of Ogangan River Source: Author's Fieldwork (2019) 
cassava before its processing for cassava flake (Fig. 2). The agro-industry within the riparian area of Ogangan River also makes use of it for oil palm production (Fig. 4). These human activities are fast spreading to all segment of the river, from upstream to downstream. The attribute of Ogangan River, being a perennial river has attracted various landuse to it. However, various human activities within the riparian corridor has various impacts on the riparian area. Most of these impacts are negative, as they affect productivity of the riparian zone significantly. The impacts of these landuses on the riparian corridor are also discussed.

\subsection{Impact of Agriculture and Other activities in Ogangan River Riparian Corridor}

Nationwide, agriculture is probably the largest contributor to the decline of riparian area quality and functioning [10]. Because some of the most fertile soils are often located in riparian areas, there is an economic incentive for their conversion to cropland. These areas are also convenient sources of water for irrigation of adjacent cropland.

The major impact of agriculture on riparian areas has been their conversion to other plant species via such as forestry, row crop agriculture, and livestock grazing. The periodic removal of trees by forestry has the potential to alter the long-term composition and character of riparian forests. Where large portions of the standing timber are harvested or where the period between harvest operations is short, substantial changes to the composition, structure, and function of riparian forests will almost certainly result. The harvest of riparian forests can increase the amount of solar radiation reaching a stream, which can increase water temperatures and affect aquatic primary production. The removal of vegetative cover can impair the ability of riparian areas to retain water, sediment, and nutrients such as nitrogen and phosphorus. In general, the effects of human activities on riparian structure and function are much greater when forests are clear-cut or harvested right up to stream banks and lake shorelines.

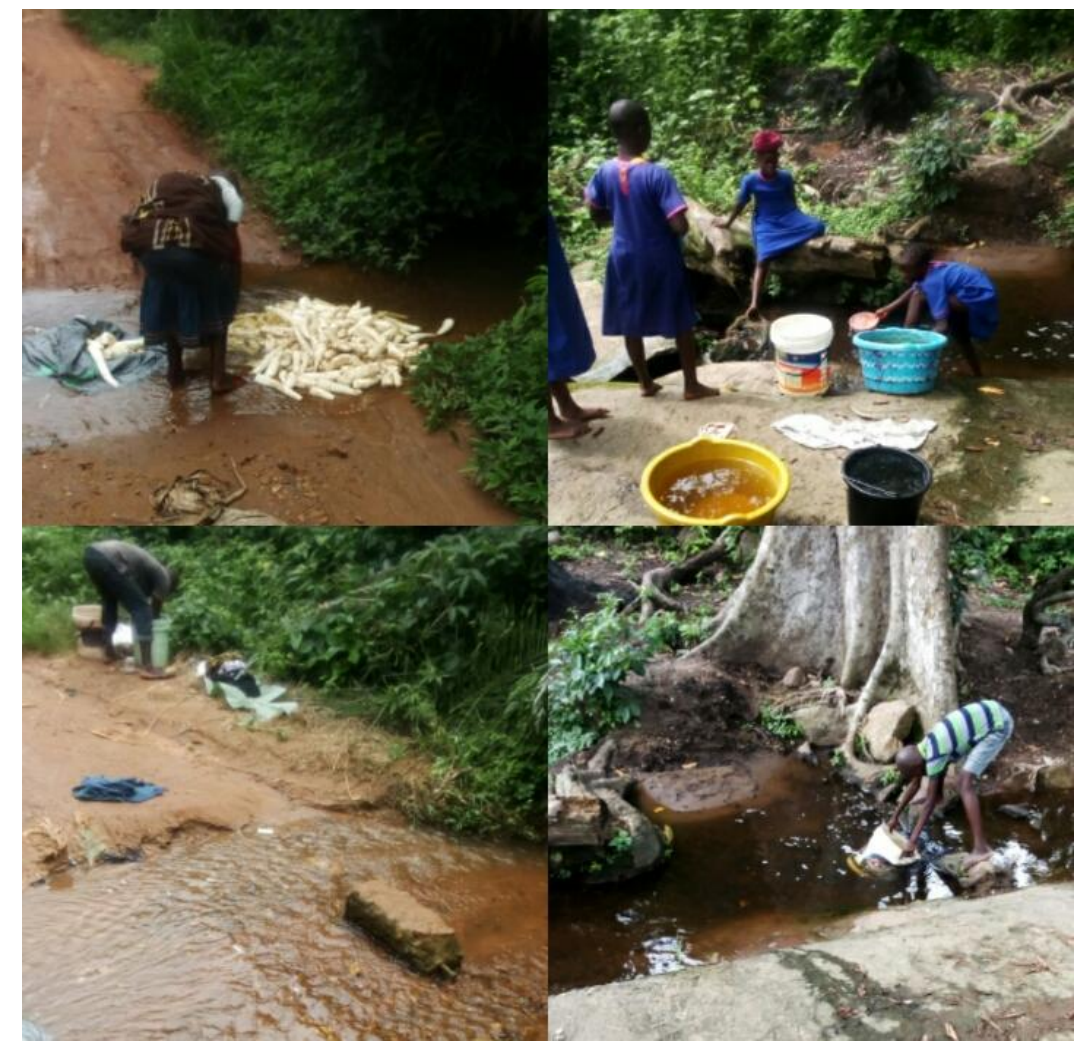

Fig. 2. Various uses of the Ogangan River Source: Author's Fieldwork (2019) 


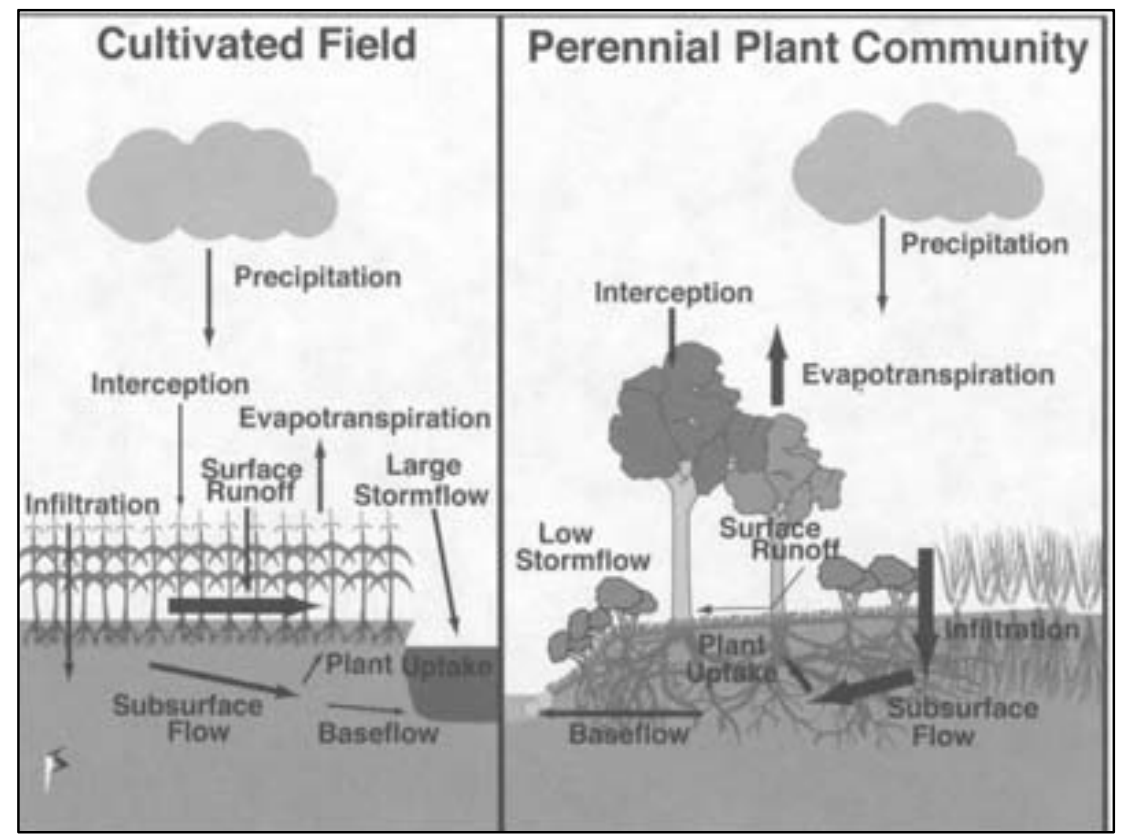

Fig. 3. Differences in water movement in a non-tiled annual row-crop field and a perennial riparian forested buffer. (Schultz, et al. 2000, by American Society of Agronomy)

Furthermore, urbanization and the accompanying increase in impervious surfaces have modified watershed hydrology and vegetation, and consequently the structure and functioning of riparian areas. As vegetation is replaced by impervious surfaces (roads, buildings, parking lots), infiltration, groundwater recharge, groundwater contributions to streams and stream base flows all decrease, while overland flow volumes and peak runoff rates increase. Stream channels respond by increasing their crosssectional area to accommodate the higher flows. This channel instability triggers a cycle of stream bank erosion and habitat degradation [11,12].

Concentrated agriculture within the riparian zone of Ogangan river has converted most of the area into croplands. The effects of excessive agricultural practices on riparian areas are drastic. Under natural settings, riparian vegetation protects the soil surface, and soil fauna and flora are constantly creating macro pores, which maintain high infiltration and percolation rates. When land is converted for agriculture, particularly row crops, vegetative cover is reduced, which exposes soil to raindrop impact and surface sealing, thereby decreasing infiltration. Although agricultural tillage does help to maintain porosity in soil, which promotes infiltration and percolation, it does not do so to the extent achieved by undisturbed populations of soil flora and fauna. The machinery used in tilling can also compact soils [11,12].

Together, these practices alter the rates, such that adjacent riparian areas trap substantial amounts of sediment [10]. Over time, the upslope portion of the riparian area evolves into a terrace that, if not managed via tillage, can hinder further inflow. When this occurs, runoff flows parallel to the riparian area until a low point or drainage way is reached. The diverted overland flow enters the riparian area as concentrated flow, which again reduces its effectiveness for water-quality protection.

There is more overland flow and less total evapotranspiration result in larger storm flow in the row-crop field while in the perennial riparian plant community, higher rates of infiltration and annual evapotranspiration reduce storm flow and increase base flow [11,12].

Furthermore, agricultural chemicals (both pesticides and fertilizers) in overland flow can also negatively impact fauna and flora located in riparian areas and downstream receiving waters of Ogangan River. Similarly, fertilization can cause nutrient losses from the land to nearby streams to increase by an order of magnitude or more. Asides pollution from agricultural activities, residents around the river dump refuse at a site 


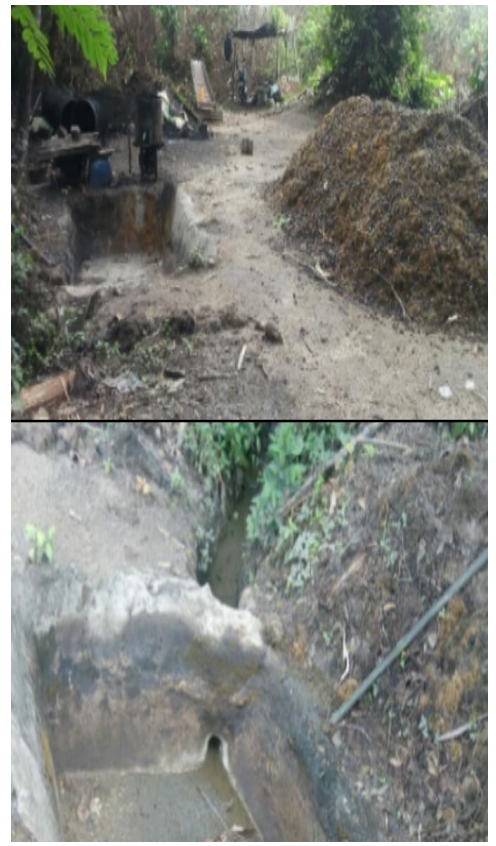

Fig. 4. Oil palm mill

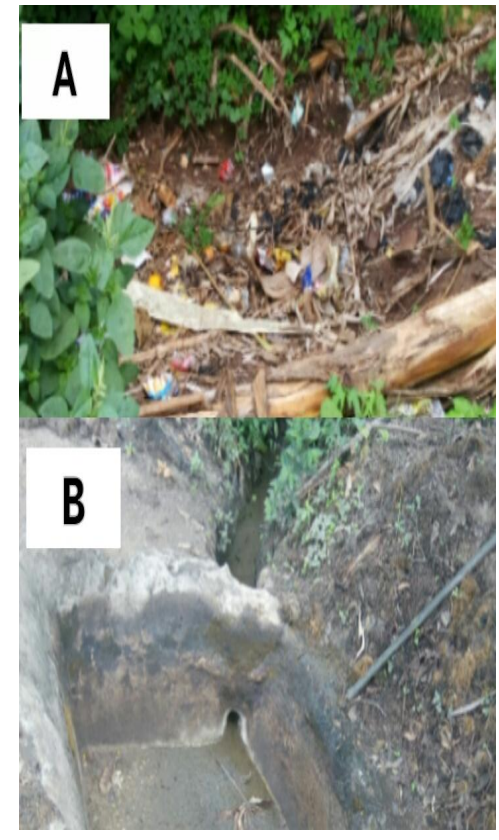

Fig. 5. Waste dump site (A) and palm oil mill waste passage (B)

Source: Author's Fieldwork (2019)

close to the river; some of these wastes find their way into the river, especially through erosion.

Also the waste discharge from the palm oil mill at the upstream of the river was traced to flow back into the river (Fig. 5). This can result in death of some aquatic organisms in the river.

Continuous riparian vegetation removal by human activities in the riparian zone of Ogangan river, have exposed the area to erosion. When erosion occurs, especially at a very high rate, sediments are carried from upland by flowing water into the river, the river is gradually being silted up, as the area it covers is reduced compared to few years ago. If this continues, it can cause eutrophication of the river and end the lifespan of the riparian zone of the stream, if necessary measures to combat this problem are not taken.

\section{SUMMARY OF FINDINGS}

As population increases, human activities also increase. The beneficial features of riparian areas through the environmental and economic benefits it produces, attracts various human activities especially agricultural activities. The riparian zone of Ogangan River is not left out of this fact. The observation and analysis in this study indicated that, human activities are rapidly increasing in the riparian zone than ever, as more people spread to reside in the area. It should however be noted, as stated in this study that, uncontrolled human activities have detrimental effects on the riparian zone of the river.

\section{CONCLUSION}

This study revealed that there is a fast rate of increase of human activities in the riparian area of Ogangan River. Agricultural activities and urbanization processes and its pathways were identified to be major proximate causes of this threat on the zone. This unprecedented rate of human activities in the study area is degrading the capability of the riparian zone to provide ecosystem services.

\section{RECOMMENDATION}

Riparian systems typically cut through diverse landscapes, crossing political, social, cultural, and boundaries. There is a critical need to implement nationwide, activties that are "riparian friendly" and that are effective at eliminating or significantly reducing many of the potentially 
adverse effects of existing human activities within the zone; Such as enforcement of the watershed management regulation for protection of $150 \mathrm{~m}$ from the sides of rivers. The state government should implement law for the protection of riparian habitat. This law should be accompanied with implementing mechanism for its sustainability.

\section{COMPETING INTERESTS}

Authors have declared that no competing interests exist.

\section{REFERENCES}

1. Mira $O$. Land use changes in central Kenya from the 1950s-A Possibility to Generalise? Geo Journal. 2004;51:203209.

2. Erickson, Fay. Great basin riparian ecosystem, ecology, management and restoration. Washington D.C: Society for ecological restoration international; 2011.

3. Allan JD. Landscapes and riverscapes: the influence of land use on Stream ecosystems. Annual Review of Ecology, Evolution and Systematics. 2004;35:257284.

4. Arizona Riparian Council Fact Sheet I. Arizona State University, Center For Environmental Studies, Tempe, AZ. 1988; 85287-1201.

5. National Research Council (NRC). Watershed management for potable water supply: Assessing the New York City Strategy, National Academy Press; 2000.

6. National Research Council (NRC). Watershed management for potable water supply: Assessing the New York City Strategy, National Academy Press; 2000.

7. Alaigba T. Influence of land use activities on riparian vegetation, soil and water quality: An Indicator of Biodiversity Loss, South West Mau Forest, Kenya. Open Journal of Forestry. 2015;6:373-385.

8. Chambers JC, Miller JR. Great basin riparian ecosystem, ecology, management and restoration. Washington D.C: Society for ecological restoration international; 2004.

9. Vivek S, Marina A. Exploring the role of vegetation fragmentation on aquatic conditions: Linking upland with riparian areas in Puget Sound lowland streams. Landscape and Urban Planning. 2009;90: 66-75.

10. Dillaha TR. Vegetative filter strips for nonpoint source pollution control. Transactions of the ASAE. Ark July 9. USDA For. Serv. Gen Tech Rep. RM 43. 2017;32(2):491-496.

11. National Research Council, U.S. Riparian areas, functions and strategies for management. Washington D.C.: The National Academies Press; 2002.

12. National Research Council, U.S. Riparian areas, functions and strategies for management. Washington D.C.: The National Academies Press; 2002.

(c) 2019 Shittu et al.; This is an Open Access article distributed under the terms of the Creative Commons Attribution License (http://creativecommons.org/licenses/by/4.0), which permits unrestricted use, distribution, and reproduction in any medium, provided the original work is properly cited.

Peer-review history:

The peer review history for this paper can be accessed here: http://www.sdiarticle4.com/review-history/52857 